\title{
Tatuagens, Piercings e Diversidade Cultural: o Que Gestores Dizem Sobre Esse Tema?
}

\author{
Flávia Lorenne Sampaio Barbosa \\ Universidade Federal do Piauí - Brasil \\ flsbarbosa@hotmail.com \\ Alzirene dos Santos Brito \\ Universidade Federal do Piauí - Brasil \\ alzirenebrito@bol.com.br
}

\section{Fabiana Pinto de Almeida Bizarria \\ Universidade de Fortaleza - Brasil \\ bianapsq@hotmail.com}

\section{Resumo}

A diversidade cultural, representada pela utilização de tatuagens e piercings, possui variados impactos nos fenômenos sociais. No âmbito organizacional, sua gestão propicia potencialidades, especialmente como oportunidade para harmonizar ambientes corporativos e agregar valor competitivo. A pesquisa investiga a percepção sobre a empregabilidade de pessoas adeptas à tatuagens e piercings no contexto da gestão da diversidade cultural. Realizou-se pesquisa de campo com 8 empresários de uma cidade do interior do estado do Piauí, por meio de entrevistas semiestruturadas, analisadas com suporte na análise de conteúdo, especificamente, análise relacional. Com auxílio do software Atlas ti, categorizou-se as entrevistas em torno da gestão da diversidade cultural e duas subcategorias: cultura organizacional, formada pela dimensão valores sobre a diversidade e relações interpessoais; e resultados, formada pelas dimensões imagem e objetivos organizacionais. Constata-se que nas empresas do estudo não há gestão da diversidade, haja vista que os valores pessoais e organizacionais ainda não incorporaram valores culturais da diversidade. Em relação à empregabilidade, os objetivos institucionais refletidos nas políticas de gestão de pessoas, condicionam as competências, habilidades e atitudes profissionais ao atendimento de normas prescritas, reduzindo as possibilidades de gestão do potencial da diversidade na organização, em função do recrutamento e seleção de um perfil ideal. Acredita-se que pesquisas em outras contextos, inclusive de natureza comparativa, pode agregar novos pontos de vista e ampliar a discussão da gestão da 
diversidade no âmbito de sua afirmação como prática capaz de transformar organizações em espaços de maior acolhimento e mais competitivos.

Palavras-Chave: gestão, diversidade cultural, tatuagens, piercings 


\title{
Tatuagens, Piercings e Diversidade Cultural: o Que Gestores Dizem Sobre Esse Tema?
}

\author{
Flávia Lorenne Sampaio Barbosa \\ Universidade Federal do Piauí - Brasil \\ flsbarbosa@hotmail.com \\ Alzirene dos Santos Brito \\ Universidade Federal do Piauí - Brasil \\ alzirenebrito@bol.com.br
}

\section{Fabiana Pinto de Almeida Bizarria \\ Universidade de Fortaleza - Brasil \\ bianapsq@hotmail.com}

\begin{abstract}
Cultural diversity, represented by the use of tattoos and piercings, has varying impacts on social phenomena. At the organizational level, its management provides potential, especially as an opportunity to harmonize corporate environments and add competitive value. The research investigates the perception of employability of people adept to tattoos and piercings in the management of cultural diversity. He conducted field research with eight business of a city in the state of Piaui, through semi-structured interviews, analyzed with support in content analysis, specifically, relational analysis. With the help of Atlas ti software, the interviews were categorized-around management of cultural diversity and two subcategories: organizational culture, formed by the dimension values of diversity and interpersonal relationships; and results formed by the dimensions of image and organizational objectives. It is noted that the companies in the study there is diversity management, given that personal and organizational values have not yet incorporated cultural values of diversity. Regarding employment, the institutional objectives reflected in people management policies, determine the skills, abilities and professional attitudes service prescribed standards, reducing the potential management opportunities of diversity in the organization, according to the recruitment and selection of ideal profile. It is believed that research in other contexts, including comparative in nature, can add new views and increase the diversity of management discussion in his statement as a practice capable of transforming organizations into spaces of greater attention and more competitive.
\end{abstract}


Keywords: management, cultural diversity, tattoos, piercings 
Modificações corporais como expressões de aspectos subjetivos são observados desde épocas remotas e estão presentes em diferentes culturas, sendo a pele o principal veículo para essas expressões (Osório, 2006, Rodrigues, \& Carreteiro, 2014). Experiências de tatuagem e piercings são encontradas em rituais de passagem e como forma de tornar o corpo mais belo (Rodrigues \& Carreteiro, 2014). No Ocidente, se estabeleceu como prática configurada em consonância com aspectos sociais que impregnaram estigmas, associando seu uso a determinados grupos, como marginais e criminosos (Goffman, 1988, Odorizzi, 2010). Também foi identificado sua prática como emblema de movimentos contra culturais, como, por exemplo, hippies e punks (Goffman, 1988, Caroni \& Grossman, 2012, Rodrigues \& Carreteiro, 2014). Nesse sentido, a linguagem corporal idealizada pela tatuagem e pelo piercings assume posição de rompimento da norma social, imbuído de concepções “políticas, éticas e estéticas” (Rodrigues \& Carreteiro, 2014, p. 748).

Ao longo do século XX, a tatuagem e o piercing assumiram novo status, permeando novos lugares sociais em que as existências dessas marcas assumem conteúdo menos transgressivo e negativo (Rodrigues, \& Carreteiro, 2014), sendo prática mais utilizada, em especial, pelo público jovem, como forma de constituição de identidade diante do contexto cultural (Moreira, Teixeira, \& Nicolau, 2010).

No que tange ao mercado de trabalho, contata-se que a experiência estética tem sido tema de importantes debates (Odorizzi, 2010). A valorização da imagem ainda preconiza um perfil ideal e que é transposto em modelos estéticos esperados pelos empregadores. A expectativa em torno de um determinado padrão, alimenta estigmas perniciosos nos diversos contextos de trabalho (Negri, 2011).

O estudo sobre a diversidade no âmbito laboral enfatiza grupos sociais que são colocados tradicionalmente a margem, como as mulheres, os negros e os portadores de algum tipo de deficiência, e problemas advindos da diversidade, como, por exemplo, o preconceito e o assédio (Nkomo \& Cox, 2007). Estudos apontam a relação de preconceito com esses grupos, ressaltando o tratamento desigual e as consequências diretas para a satisfação no trabalho, a saúde e a qualidade de vida das pessoas inseridas nesse processo (Weichselbauner, 2000, Bhui, Stansfeld, Mackenzie, Karlsen, Nasroo, \& Weich, 2005). Da mesma forma, há evidências sobre a existência de estigmas culturais que subsidiam decisões nos processos de seleção e de ascensão profissional (Gilbert, Carr-Rufino, Ivancevich, \& Lownes-Jackson, 2003). Assim, declara-se a necessidade de políticas de promoção da 
diversidade cultural nas empresas (Myers, 2003, Torres, \& Pérez- Nebra, 2004), por meio da gestão da capacidade organizacional para atuar em torno dessas diversidades (Cox \& Blake, 1991).

A análise da utilização de tatuagens e piercings no trabalho suscita reflexões em torno de uma nova manifestação da diversidade, especialmente quando se tem como referência os estigmas dessas modificações corporais, impostas pela sociedade, uma vez que a cultura dos ambientes corporativos ainda preconiza uma imagem profissional formal (Odorizzi, 2010). A rejeição se manifesta, notadamente, quando se considera a aparência um aspecto importante para o recrutamento e a contratação de novos trabalhadores, com o argumento de que ao usar tatuagens e piercings, os candidatos não transmitem maturidade e seriedade essencial para desempenhar suas atribuições laborais (Odorizzi, 2010, Rodrigues \& Carreteiro, 2014), haja vista que ainda se considera que "os atributos físicos, além da competência técnica, são essenciais para a inserção no mercado de trabalho”. (Paim, 2007, p. 42).

A Gestão da Diversidade Cultural emerge nesse contexto à medida que o aumento da diversidade nas organizações é problematizada sob a ótica da capacidade organizacional para gerir essa força de trabalho em prol da eficácia organizacional (Nkomo \& Cox, 2007). Assim, processos de contratação podem refletir concepções da diversidade cultural presentes na gestão organizacional.

Nessa perspectiva, o ensejo dessa pesquisa corresponde a análise da contratação de pessoas adeptas ao uso de tatuagens e piercings, na perspectiva da diversidade cultural. Sendo a contratação parte do processo de gestão da diversidade cultural, por meio da análise da atração e da retenção de profissional pode-se apreender aspectos dessa gestão, caso ela seja uma prática organizacional, e, também, disposições gerenciais correlatas à essas gestão.

Diante das considerações, parte-se do seguinte questionamento: Qual a percepção de gestores de empresas situadas em um município do estado do Piauí, em relação à contratação de pessoas com tatuagens e piercings?

A pergunta suscita a necessidade de investigar a percepção de gestores de empresas sobre a empregabilidade de pessoas que fazem uso de tatuagens e piercings, E, de forma específica, discutir essas marcas corporais no contexto da gestão da diversidade cultural. 


\section{Tatuagem, piercing e Mercado de Trabalho}

A tatuagem é a mais famosa forma de modificar o corpo no mundo (Rocha, 2009). No período das cavernas, a representação gráfica e a pintura com características sobrenaturais e naturais já faziam parte do dia-a-dia (Berger, 2006). Em diferentes partes da América do sul foram encontradas estátuas de pessoas que existiram há mais de dois mil anos e mostram que usavam piercings nos lábios e no nariz (Silva, 2010). Um dos primeiros registros foi descoberto nos Alpes em 1991, onde foi encontrada uma múmia com cerca de 5,3 mil anos que ficou conhecida como Homem do Gelo (Rocha, 2009). No Egito Antigo foram encontradas múmias femininas que possuem pontos e traços escritos no abdome, o que provavelmente indicava adoração à fertilidade (Rocha, 2009).

A tatuagem moderna ocidental, esteve historicamente ligada à marginalidade social e econômica, nos corpos de prostitutas, marinheiros e criminosos (Leitão, 2004). As técnicas e as regulamentações da tatuagem vêm sendo aprimorada com o tempo (Rocha, 2009). Nos anos de 1990, os estúdios de tatuagem começaram a se profissionalizar, agregando equipamentos modernos, materiais esterilizados e outros descartáveis e alguns equipamentos médicos (Pérez, 2006).

A utilização de tatuagens e piercings estabelece formas de sociabilidade e interação peculiares (Braz, 2006). Podem ser explicadas por razões estética ou parte de um ritual, indicando marcas tribais, ritos de passagem, ritos propiciatórios, signos de status social, crenças, ideologias e estilos, uma vez que os indivíduos entram em um processo estrutural e histórico que potencializa e propaga a comunicação (Berger, 2006).

Contata-se que a tatuagem vem ganhando novos significados, saindo da marginalidade e se dissociando de um estigma pernicioso, que legitima a segregação social, para características comportamentais julgadas "naturais" e "comuns" (Pérez, 2006, Coimbra, Pacheco \& Saraiva, 2014). Os adeptos têm assumido a tatuagem e o piercing de variadas maneiras, sem restrições de idade, gênero ou status, em consequência de uma maior aceitação social (Monteiro, Villela, \& Soares, 2014).

De todo modo, a experiência do pré-julgamento, ainda não extinta, indica a existência de características negativas e é, ainda, vivenciada pelas pessoas que fazem uso desses adereços (Fleury, \& Torres, 2007, Silva, 2010), pois “embora as modificações corporais tenham se tornado lugar-comum, esta prática ainda é, frequentemente, associada à 
anormalidade" (Caroni \& Grossman, 2012, p. 1064), eivada de estereótipos que fundamentam comportamentos de segregação (Klaczynski, Goold, \& Mudry, 2004).

Os estigmas, por sua vez, são reflexo de um processo cognitivo de base para formulações sobre categorização social, manifesta como maneira de organizar as informações sobre o mundo, dando forma, conteúdo e hierarquia aos fenômenos do entorno (Bar-Tal, 1997). Dessa forma, atribui-se valor aos grupos em conformidade com a cultura e a interação social dos sujeitos envolvidos.

No âmbito laboral, as diferenças em função dos estigmas, repercutem no âmbito da gestão da diversidade das organizações, especialmente no âmbito da análise da empregabilidade de pessoas pertencentes a diferentes culturas (Weichselbauner, 2000). Dessa forma, a concepção sobre a diversidade nas empresas reflete em investigações que apontam duas perspectivas de análise: a leitura do sujeito de cultura diversa que, sendo integrado a dinâmica organizacional partilhará de ambiente mais favorável ao seu bem-estar e, a oportunidade que a diversidade oferece para que as empresas tenham em seu repertório maior capacidade de adaptação às mudanças contextuais, bem como, a ampliação do seu escopo de atuação e criação de vantagens competitivas (Cox, \& Blake, 1991).

No que tange especificamente à análise da gestão da diversidade no âmbito da empregabilidade, nos processos tradicionais de recrutamento o seleção, "a avaliação da aparência física pode se tornar, e quase sempre se transforma, em um mecanismo de atribuição de status, de classificação de outros e relações de dominância” (Paim, 2007, p. 32), haja vista que "as avaliações não se restringem às competências profissionais, mas aos aspectos exteriores que demarcariam as condições de acesso ao emprego" (Paim, 2007, p. 32). Ainda persistem, no entanto, as demandas de modificar a aparência física para se adequar ao "perfil profissional" e conseguir se empregar especialmente em cargos que exijam o atendimento direto ao público (Neves, 2013, Paim, \& Pereira, 2010).

\section{Gestão da Diversidade Cultural}

Os novos contextos de trabalho são marcados por organizações com quadro de funcionários reduzidos, horizontalizados, com forte uso da terceirização, e a emergência de novos modelos de gestão, com configurações heterogêneas e velocidades distintas (Gonçalves, 1997, Souza, \& Peixoto, 2013). Os trabalhadores vivenciam intensa competitividade e exigência de perfis cada vez mais ágeis, flexíveis, competentes, criativos e 
estão em constante adesão às diferentes representações profissionais ideais para esse contexto e, assim, assumem a qualificação, a aparência e as competências requeridas pelas organizações (Souza \& Peixoto, 2013, Torres da Paz \& Neiva, 2008).

A relação que equaciona as pessoas e os espaços laborais, direcionando-as para as organizações, é administrada pelas unidades de gestão de pessoas, responsáveis pelo recrutamento e a seleção de pessoas com perfil exigido pelas organizações (Coradini \& Murini, 2009). Esse setor administra a relação da empresa com seus funcionários por meio de variadas técnicas para avaliar o comportamento humano e identificar as peculiaridades ideais para cada vaga, de forma que a empresa possa otimizar resultados, economizar recursos e gerir vantagens competitivas (Coradini \& Murini, 2009, Michel, 2007). Para tanto, é preciso vontade, preparo, atenção e conhecimento para planejar e realizar recrutamento e seleção de forma coerente com os objetivos institucionais (Scanavez \& Alves, 2009), apreendendo as competências e o potencial a ser desenvolvimento pelo candidatos, em função das mudanças no mercado, traduzidas nos diferentes segmentos culturais que representam a sociedade.

As empresas se deparam com mudanças conjecturais e transferem sua necessidade de adaptação estratégica ao potencial criativo e inovativo de seus colaboradores (Pettigrew, 1987, 2012), a medida que se entende que a organização não vive ilhada e de que é uma entidade abstrata formada por redes de relações entre pessoas que buscam satisfazer interesses individuais e objetivos institucionais (Teixeira \& Monteiro, 2008). Para tanto, exige-se profissionais com habilidades, conhecimentos e atitudes para o ambiente competitivo, profissionais proativos, que sejam capazes, inclusive, de participar do processo de gestão, com formação abrangente, multiprofissional, e com maturidade para atuar em circunstâncias de imprevisibilidade (Pires, Ott, \& Damacena, 2009).

Diante desse panorama, os perfis desejados não parecem ser estáticos ou categóricos. Abrem-se outras possibilidades, quando a premissa é atuar em ambiente de mudanças. A gestão da diversidade surge como proposta de análise da dinâmica da empregabilidade, a medida que as diferentes ideias, concepções de mundo, impulsionam novas forma de atuar por meio da criatividade. Além disso, a relação entre líderes e liderados, no que tange a diversidade, pode contribuir para ambientes humanamente saudáveis (Teixeira \& Monteiro, 2008).

Os estudos que analisam as diferenças culturais, o seu relacionamento com os valores culturais e seu impacto em fenômenos sociais estão produzindo interessantes achados nas 
ciências sociais (Torres \& Dessen, 2008). Baseiam-se na compreensão de cultura como um conjunto de cognições compartilhadas pelos membros de uma unidade social, tendo os valores básicos como guia para o comportamento individual (Bilky \& Jehn, 2008). Assim, "a congruência entre valores individuais e organizacionais é considerada decisiva para a adequação indivíduo-organização”. (Bilky \& Jehn, 2008, p. 225).

Quando se analisa questões de preferência dos sujeitos, abordam-se valores que alimentam necessidades, crenças, desejos e aspectos que moldam a personalidade e a história de vida, em contínuo processo de construção (Zanelli \& Silva, 2008). A estrutura de valores possui a característica de guiar a vida, de maneira geral (Tamayo, 2007). Os valores são referência para as atitudes e os comportamentos construídos na inserção social, mediada pela experiência vivida e compartilhada pelas pessoas cotidianamente (Borges \& Alvaro, 2013, Silva, Zanelli, \& Tolfo, 2013).

Nesse escopo, os valores culturais servem para estabelecer normas compartilhados que definem o tipo de comportamento apropriado nas diversas situações (Torres \& Dessen, 2008). A estrutura organizacional é, assim, compreendida “como representação dos valores e interesses de atores organizacionais e institucionais. A estrutura organizacional seria um produto da cultura, constituindo um reflexo dos valores, ideias e arquétipos presentes". (Torres da Paz \& Neiva, 2008, p. 281).

Cox e Blake (1991) desenharam uma proposta de análise que privilegia o estudo da diversidade nas organizações com suporte nas dimensões individuais, grupais e organizacionais, dispostas em diversos segmentos organizacionais (figura 1), com amparo na migração de organizações tradicionais (sem gestão da diversidade), para empresas multiculturais (com gestão da diversidade). Esse cenário de mudança responde a modificação de valores que sustentam os arranjos organizacionais, haja vista que "estruturas e processos são sustentados por valores e preferências por certos cursos de ação e resultados”. (Torres da Paz \& Neiva, 2008, p. 282). 


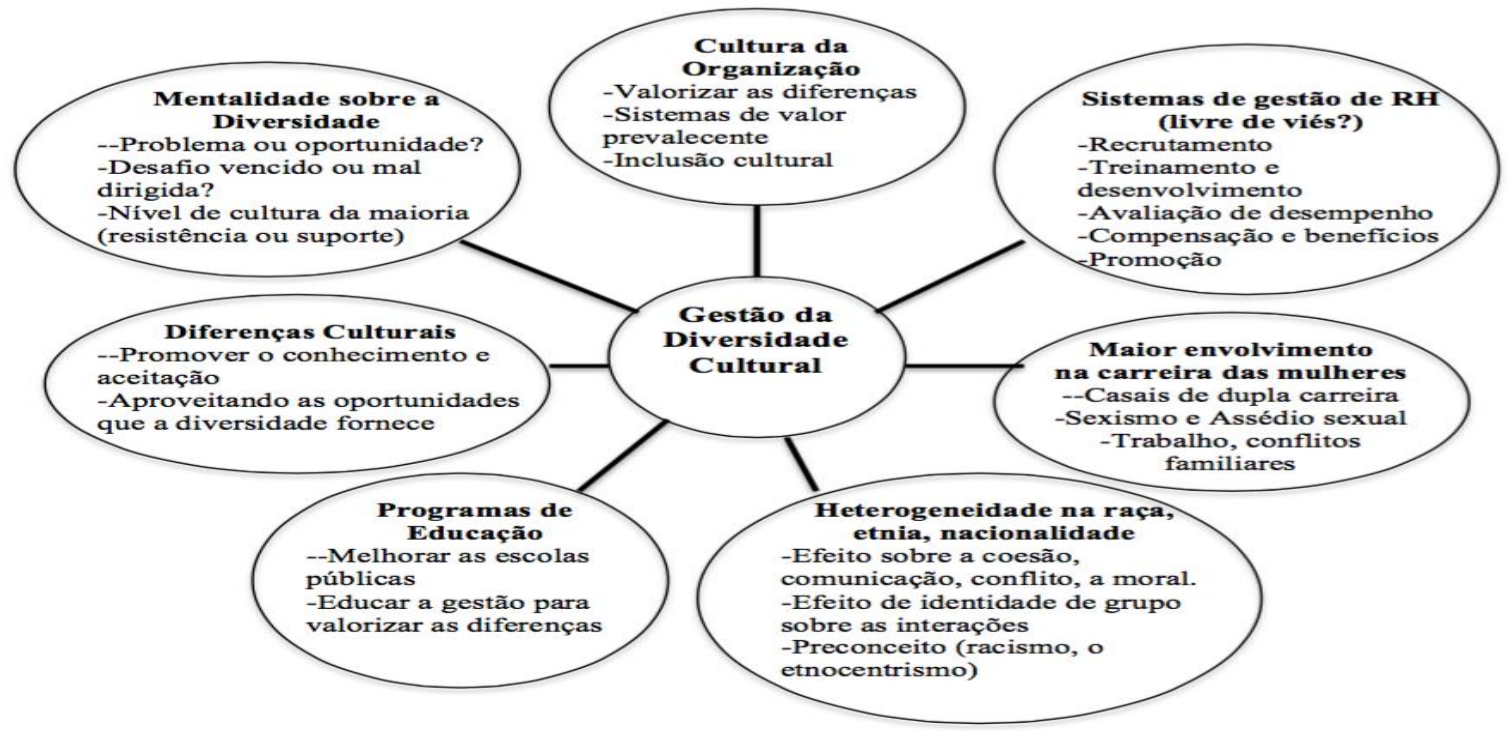

Figura 1. Esferas de atividade na Gestão da Diversidade Cultural Fonte: Adaptado de Cox e Blake (1991, p. 46)

Com o aumento da diversidade cresce o interesse pela gestão da diversidade cultural, no sentido de melhorar a eficácia organizacional para gerar vantagens competitivas, com suporte no aumento da capacidade organizacional para gerir esta diversidade (Nkomo \& Cox, 2007), haja vista que “organizações que não conseguem fazer alterações necessárias para usar com mais sucesso e manter os funcionários de diferentes origens pode esperar para sofrer uma significativa desvantagem competitiva em comparação com aqueles que o fazem”. (Cox \& Blake, 1991, p. 47).

A teoria afirma que a capacidade das organizações para atrair, reter e motivar as pessoas por meio da gestão da diversidade cultural pode levar a vantagens competitivas em estruturas de custo, por conseguir manter recursos humanos de alta qualidade, favorecendo a coesão, a comunicação, a resolução de conflitos, e a identidade grupal (Cox \& Blake, 1991, p. 50) e, por isso, a gestão da diversidade potencializa as melhores decisões, sendo a diversidade compreendida como oportunidade. Dessa forma, infere-se que a cultura organizacional para a diversidade é reflexo do conhecimento, da aceitação e consciência da diversidade, o que favorece o trabalho colaborativo e otimização da criatividade e da inovação.

Por fim, Cox e Blake (1991) direcionam atenção aos sistemas de recursos humanos, na perspectiva de problematizar a gestão da diversidade no âmbito do recrutamento, treinamento, desenvolvimento, avaliação, benefícios e promoção. A análise indica que o sistema deveria ser isento de pré-julgamentos, a medida que a gestão da diversidade inicia 
com a oportunidade de atrair e reter talentos que possam surgir em função das diferenças com foco nos diferenciais competitivos.

Portanto, a gestão da diversidade na concepção de Cox e Blake (1991) centraliza a discussão de como as diferenças no ambiente organizacional podem ser geridas para agregar valor e gerar uma melhor posição no mercado, em virtude da ampliação dos recursos advindos de uma maior capacidade de criatividade, maior relacionamento com os clientes, em função da reputação e credibilidade adquiridas com o marketing da gestão da diversidade. Esta posição dialoga com a perspectiva dos valores subjacentes a diversidade, a medida que "ação e valores são mutuamente interdependentes, delineando e refletindo a dinâmica dos membros organizacionais”. (Torres da Paz \& Neiva, 2008, p. 282).

Da mudança de atitude em relação a configuração organizacional, de uma estrutura centrada na resposta aos contextos externos, para a projeção de uma estrutura que direciona mudanças para adequação de seus sistemas para o cenário da diversidade, tem-se que, “a mudança de valores organizacionais é um processo longo e dependente do jogo interativo das necessidades pessoais e organizacionais”. (Torres da Paz \& Neiva, 2008, p. 292) e os "fatores que habilitam a organização para mudança são dependentes de poder e capacidade de ação na dinâmica intraorganizacional” (Torres da Paz \& Neiva, 2008, p. 276). Portanto, a gestão da diversidade no âmbito das empresas é função de mudanças de valores subjacentes a novas configurações das esferas organizacionais para acomodar outras estruturas de pensamento e ação, o que promulgaria a eficácia organizacional.

Embora o estudo de Cox e Blake (1991) tenha sido realizado há mais de 20 anos, pesquisas mais recentes indicam que sua estrutura de análise representa uma importante contribuição para o estudo da diversidade nos contextos organizacionais, especialmente na investigação de temas correlatos a gestão de pessoas (Pereira \& Hanashiro, 2010, Justo, 2012).

\section{Metodologia}

Realizou-se pesquisa de campo (Vergara, 2009) na cidade de Floriano, estado do Piauí, por meio de uma abordagem compreensiva de relações e percepções de um determinado fenômeno, objetivando produzir conhecimento sobre o objeto de investigação (Minayo, 2007). A investigação objetiva compreender características de determinada população, ou 
seja, seus valores, concepções e atitudes relacionadas à diversidade cultural, especificamente nas concepções sobre a empregabilidade de pessoas adeptas a tatuagens e piercings.

Foram selecionadas 15 empresas na cidade mencionada por meio do critério de acessibilidade e impacto na economia local. Dessas 15, 8 empresários aceitaram participar da pesquisa (Quadro 1).

\begin{tabular}{|c|c|c|c|c|c|c|}
\hline Empresa & Tipo & Gênero & Filhos & $\begin{array}{c}\text { Est. } \\
\text { Civil }\end{array}$ & $\begin{array}{c}\text { Tempo } \\
\text { de } \\
\text { Empresa }\end{array}$ & Escolaridade \\
\hline A & $\begin{array}{c}\text { Prestação de serviços } \\
\text { em informática }\end{array}$ & Masc. & 03 & Casado & 20 anos & Pós-Graduado \\
\hline B & $\begin{array}{c}\text { Comercialização de } \\
\text { móveis e eletros }\end{array}$ & Masc. & 03 & Casado & 17 anos & $\begin{array}{c}\text { Ensino Médio } \\
\text { Completo }\end{array}$ \\
\hline C & $\begin{array}{c}\text { Comercialização de } \\
\text { materiais de } \\
\text { construção }\end{array}$ & Masc. & 03 & Casado & 11 anos & $\begin{array}{c}\text { Superior } \\
\text { Completo }\end{array}$ \\
\hline D & $\begin{array}{c}\text { Comercialização de } \\
\text { gêneros alimentícios } \\
\text { e produtos de } \\
\text { limpeza }\end{array}$ & Masc. & 01 & Solteiro & 29 anos & $\begin{array}{c}\text { Superior } \\
\text { Completo }\end{array}$ \\
\hline E & $\begin{array}{c}\text { Comercialização de } \\
\text { móveis e eletros }\end{array}$ & Masc. & 00 & Separado & $\begin{array}{c}1 \text { ano e } 3 \\
\text { meses }\end{array}$ & $\begin{array}{c}\text { Superior } \\
\text { Incompleto }\end{array}$ \\
\hline F & $\begin{array}{c}\text { Prestação de serviços } \\
\text { em contabilidade }\end{array}$ & Masc. & 02 & Casado & 20 anos & $\begin{array}{c}\text { Fundamental } \\
\text { Incompleto }\end{array}$ \\
\hline G & $\begin{array}{c}\text { Prestação de serviços } \\
\text { bancários e } \\
\text { empréstimos }\end{array}$ & Fem. & 03 & Casada & $\begin{array}{c}11 \text { anos e 4 } \\
\text { meses }\end{array}$ & Pós-Graduada \\
\hline H & $\begin{array}{c}\text { Comercialização de } \\
\text { ramo óptico }\end{array}$ & Fem. & 02 & Casada & 20 anos & $\begin{array}{c}\text { Superior } \\
\text { Completo }\end{array}$ \\
\hline
\end{tabular}

Quadro 1. Perfil dos entrevistados

Fonte: Dados da Pesquisa (2015)

Os dados foram coletados entre os meses de setembro a novembro de 2014, por meio de entrevistas presenciais semiestruturadas, realizadas com um instrumento de 5 questões abertas, com a finalidade de obter informações em profundidade, alinhadas à perspectiva da entrevista qualitativa (Bauer \& Gaskell, 2002, Minayo, 2007).

Os relatos tiveram duração média de 20 minutos, cada, e foram transcritas e importadas para tratamento no software Atlas.ti, a fim de categorizar e apreciar os enunciados por meio da análise de conteúdo (Bardin, 2011), especificamente análise de relação, numa perspectiva de ir além da "frequência da aparição dos elementos do texto, mas para as relações que esses elementos mantêm entre si” (Bardin, 2011, p. 259), considerando a criatividade, imaginação e intuição dos pesquisadores, particularmente na definição dos grupos representativos e na hierarquia entre as divisões estabelecidas. 
Observa-se que esta análise de conteúdo auxilia a análise dos textos transcritos no sentido de desvelar núcleos de sentido existentes no discurso dos sujeitos para que, em seguida, sejam agrupados em categorias mais amplas (Bardin, 2011). Nesse caso, o software auxilia a investigação à medida que permite o cruzamento dos dados, buscando padrões e utilizando técnicas diferentes para possibilitar a observação do fenômeno através de múltiplas lentes (Bandeira- de- Mello, 2006).

Assim, identificaram-se padrões, práticas e percepções acerca do fenômeno investigado, inspirando a formação de redes de significados atribuídos ao uso de tatuagens e piercing por profissionais no mercado de trabalho. Para tanto, fez-se necessário rigor, perseverança e disciplina (Freitas, Cunha, \& Moscarola, 1997).

\section{Apresentação e Análise dos dados}

Inicialmente, a codificação das entrevistas ensejaram códigos que emergiram das diversas situações descritas pelos sujeitos entrevistados. Cada um foi sugerido considerando a relevância dos enunciados para a pesquisa, as categorias de Cox e Blake (1991) e o impacto da apreciação do uso das tatuagens e piercing para a eficácia organizacional. Indicou-se, como ponto de partida, a categoria "Gestão da Diversidade Cultural”, que se apresentou como elemento subjacente as duas subcategorias evidenciadas. Assim, alinhou-se de forma direta com a subcategoria Cultura Organizacional e, indiretamente, a subcategoria Resultados, tendo em vista representar o objeto de investigação (Figura 2).

Em seguida, o teor das entrevistas suscitaram a elaboração de outros grupos que permearam o entendimento das subcategorias elencadas. Sendo, valores/diversidade e relacionamento interpessoal no que concerne a Cultura Organizacional. E, no que tange a eficácia organizacional, denominado de Resultados, a imagem e objetivos organizacionais. O que se prevê é uma hierarquia estabelecida em torno de cada grupo. 


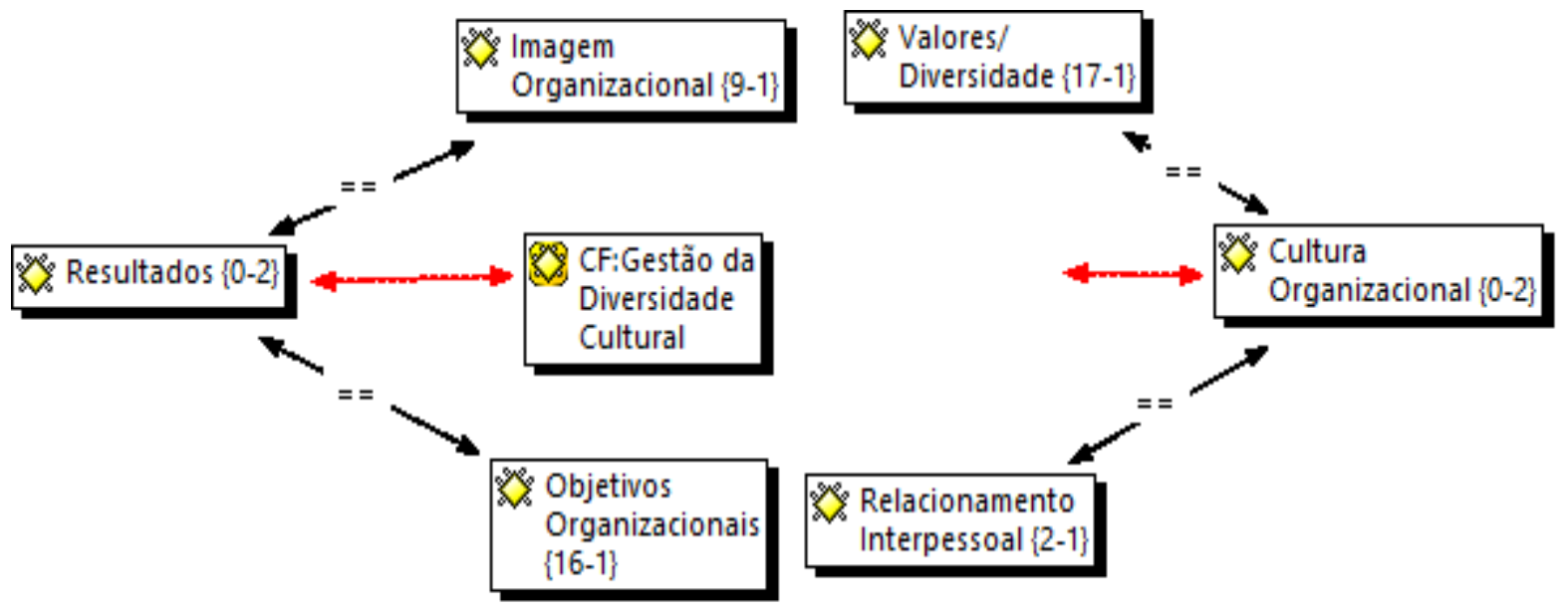

Figura 2. Categorias constituídas com suporte nos dados da pesquisa.

Fonte: Dados da pesquisa (2015)

\section{Cultura organizacional-Valores/Diversidade}

O mercado de trabalho se situa no contexto social e partilha valores, concepções, formas de se situar no mundo (Souza \& Peixoto, 2013). Em função disso, o ato de contratar um funcionário torna-se um fenômeno que abrange a situação de encontro entre duas pessoas, com vivencias particulares e posturas que expressam histórias de vida.

Considerar a existência de diversidade cultural é um aspecto relevante no mundo organizacional (Cox \& Blake, 1991). Nesse sentido, observa-se que a leitura dos gestores sobre o uso de tatuagem e/ou piercing, confirma que a cultura, além de marcar a subjetividade (Braz, 2006), expressando valores individuais, organizacionais e culturais (Zanelli \& Silva, 2008, Tamayo, 2007, Torres \& Dessen, 2008), é tema para discussão mais ampla (Leitão, 2004).

Considera-se que pessoas que escolham marcar o corpo com tatuagens e e/ou piercing, terão, em geral, dificuldades no mercado de trabalho. Essa afirmação parte da percepção apresentada pelos gestores que consideram essas marcas como uma ameaça para os negócios, seja pela conotação de anormalidade impregnada nos adeptos (Caroni \& Grossman, 2012), pelo teor depreciativo associado à malandragem, rebeldia, uso de drogas ou negligência (Fleury \& Torres, 2007, Silva, 2010).

(...) prefiro manter o padrão normal para a maioria, pois favorece os negócios (E1, 2015). 
A maioria das empresas não contratam, porque são vistas como malandros, (E, 2015).

(...) a gente não contrata funcionários que esteja fora da normalidade, da aparência normal (E3, 2015).

(...) você não vai colocar uma pessoa que tem uma aparência física, digamos, fora do normal pra atender uma determinada tarefa, função da empresa (E2, 2015).

(...) existem aquelas outras pessoas que fazem isso associado ao uso de algum tipo de, digamos assim, de droga $\left(\mathrm{E}_{7}, 2015\right)$.

Reforçando a apreciação sobre a vinculação imagem-subjetividade, os discursos ressaltam que os sujeitos adeptos a tatuagens e/ou piercing precisam buscar se adequar ao contexto por meio da negação da imagem, o comportamento deve ser substituído pelo que é convencionado como "normal” (Goffman, 1988, Caroni \& Grossman, 2012) . Exige-se uma postura distante da que se postula como comportamento desviante, mesmo que seja atenuado pela reiterada afirmação de que o que de fato importa, é o potencial do trabalhador em tela.

(...) porque diante dessa empresa né, pra o trabalho, mesmo que a pessoa use, a gente sempre solicita que no ambiente de trabalho, seja a parte né, visualmente (E1, 2015).

Assim, eu acho que é... uma pessoa que tem uma tatuagem muito grande à mostra como foi um dos casos aqui que tu me mostrastes (exagerado né?) exageradas, eu acho que tira um tanto quanto da credibilidade, eu acho $\left(\mathrm{E}_{3}, 2015\right)$.

(...) a gente observa é que muitas pessoas elas não sabem utilizar o piercing entendeu, elas usam em todos, em lugares que a gente olha, então aquilo não, não é uma coisa que a gente vê com bons olhos né $(. .).(E 7,2015)$.

Há diálogos que associam uso de tatuagens e/ou piercing a adolescência, não sendo compatível com a ocupação de cargos concebidos como mais tradicionais, haja vista que destoem do "padrão" (Odorizzi, 2010, Negri, 2011). Afirma-se, também, que fazer uso de tatuagens e/ou piercing é compatível com um determinado cargo, evidenciando o estereótipo que marca a investigação: imagem profissional é função categórica no mercado 
de trabalho. Atribui-se a imagem características subjetivas e comportamentais sensíveis ao julgamento social, que impacta decisões organizacionais no âmbito da gestão da diversidade.

Acho que são mais adolescentes (E5, 2015).

(...) até porque é muito difícil hoje, principalmente nos jovens, é difícil você ver um jovem pra não ter uma tatuagem $\left(\mathrm{E}_{3}, 2015\right)$.

(...) você imagina um presidente da república, um ministro, um deputado, um senador com tatuagens, com o cabelo do tamanho... isso não existe, eu acho a aparência é condizente com o cargo (E2, 2015).

No segmento de moda se encaixaria, mas na empresa não (E1, 2015).

Ainda no âmbito dos valores, há referência à cultura das pequenas cidades como forma de demarcar o ambiente contextual das empresas entrevistadas, com influências negativas nas interações sociais, avigorando a natureza negativa do sujeito tatuado, o que limita a ação gerencial a medida que há necessidade de adequação das estratégias organizacionais à características dos seus clientes.

Mas nós aqui, nós, como eu falei, a cidade do interior então eles associam muito isso, a gente sabe que isso é uma realidade nossa $(\mathrm{E} 4,2015)$.

Além disso, a presença de tatuagens e piercings é julgada conforme o impacto que possam gerar, em função do "exagero" do seus usos. Se for algo atenuado por um "disfarce”, pode receber aceitação e menos estranhamento.

(...) existem tatuagens e tatuagens, uma pessoa que utiliza uma tatuagem pequena que não, não, não... esteja tanto à mostra ela vai ser facilmente é... se ela tiver as qualificações ela vai ser facilmente contratada, agora se ela aparenta muitas tatuagens ou piercings que ficam bem à vista eu acredito que sim, que as pessoas não contratem não (E2, 2015).

Se os empregadores assumem essa posição, o mercado de trabalho é assinalado pela opressão em torno da imagem não concebida como adequada (Nkomo \& Cox, 2007). Um 
discurso velado e que negligencia o sujeito em função de sua imagem (Weichselbauner, 2000, Bhui et al. 2005).

\section{Cultura organizacional - Relacionamento Interpessoal}

Além dos valores subjacentes à análise da empregabilidade, relatos apontam que a diversidade pode gerar dificuldades no que tange as relações interpessoais, quando as marcas impactam a aceitação dos sujeitos pelos seus colegas, assim como, a aceitação dos clientes. Infere-se, por esse ponto, que os gestores reagem à situação da diversidade, sem que ações sejam delimitadas no âmbito dessa aceitação (Cox \& Blake, 1991).

(...) influenciam na imagem, tanto dos funcionários internos, na aceitação interna dos funcionários, bem como na aceitação por parte do cliente $(\mathrm{E} 1,2015)$.

(...) vejo grande harmonia e fico até muito feliz quando vejo o pessoal interagindo da melhor forma e um trabalho muito bonito em equipe (E2, 2015).

Os relacionamentos referenciados confirmam a necessidade da gestão da diversidade nas organizações e políticas que atuem de forma específica para a aceitação da diferença e, com isso, a promoção de uma ambiente de trabalho mais harmonioso (Batista, 2004, Souza \& Peixoto, 2013; Teixeira \& Monteiro, 2008). Para tanto, é importante ressaltar que "os valores organizacionais são também fortemente influenciados pelos valores humanos, gerais, que têm uma natureza inconsciente e são profundamente arraigados e estabelecidos em conformidade com os valores sociais repassados pela escola e pela família”. (Torrez da Paz \& Neiva, 2008, p. 292). Esse aspecto permite inferir que os gestores atribuem ao grupo, aos clientes e ao ambiente externo em geral valores pessoais.

Da mesma forma, a gestão da diversidade implica no maior envolvimento dos funcionários com o trabalho e, por meio dessa atmosfera, aumenta-se o potencial de aproveitamento das oportunidades advindas da diversidade, como, por exemplo, o trabalho colaborativo, a criatividade e a inovação (Cox \& Blake, 1991). 


\section{Resultados - Imagem Organizacional}

No âmbito da área de gestão de pessoas, o recrutamento e a seleção de candidatos para oportunidade de trabalho representa um importante momento para equacionar necessidades organizacionais, perfil desejado, perfil esperado, valores organizacionais e pessoais, e outros aspectos que impactam a decisão de inserir um novo elemento a teia organizacional (Coradini \& Murini, 2009). Nesse momento, há importante consideração em torno da imagem organizacional, haja vista que a reputação impacta positivamente os resultados organizacionais (Cox \& Blake, 1991).

Por meio da análise das entrevistas infere-se que a diversidade não é bem aceita pelos gestores. Em torno desse fato, há justificativas para a não aceitação plena de pessoas que possuam características diferentes das expectativas dos clientes. A imagem organizacional, nesse caso, associa-se a imagem dos funcionários e é reforçada com posições gerenciais que reforçam a segregação.

(...) essas coisas a gente por enquanto evita exatamente tentando manter a boa relação com o cliente $(\mathrm{E} 1,2015)$

(...) nós vemos muito o comportamento do nosso cliente $\left(\mathrm{E}_{3}, 2015\right)$

(...)o funcionário tem que ser a imagem da empresa $(\mathrm{E} 3,2015)$

(...) acho que toda empresa ou marca cria seu perfil e nem todo tipo físico se adequa as necessidades para manter esse perfil. (E8, 2015)

(...) Preferimos não bater de frente com a opinião da maioria da clientela (E8, 2015)

Como extensão das opiniões levantadas, há considerações sobre o tipo de empresa que melhor se adequaria a profissionais adeptos às tatuagens e piercings, quando legitimase que há variados perfis de empresas e, para adequar-se a imagem dessas instituições, profissionais com características "diferenciadas" podem atuar de maneira mais eficiente, haja vista melhor aceitação do público consumidor dos produtos/serviços dessas organizações.

No segmento de moda se encaixaria, mas na empresa não. (E4, 2015)

depende muito do tipo de empesa, como ela se relaciona com o cliente e de 
produto, pois em alguns tipos de negócio estas características até favorecem esta relação. $(\mathrm{E} 8,2015)$

No que diz respeito à imagem organizacional, infere-se da pesquisa que a concepção de contextos de mudança e das oportunidades advindas da diversidades limita-se ao ambiente externo. Assim, em geral, entende-se que para as diferentes necessidades dos mercados, há diferentes perfis de empresas e, com isso, a concepção vigente é marcada por uma leitura determinista

O cliente é que dita as regras da empresa.(E1, 2015).

(...)o mercado tá aí pra todo tipo de pessoas em relação a qualquer tipo de que venha expondo a pessoa, tem uns que gostam de mais de um tipo, outros que não gostam entendeu? .(E6, 2015)

Em suma, reporta-se a adaptação organizacional (Pettigrew, 1987, 2012) para a gestão da diversidade em função das mudanças do mercado de trabalho e do público consumidor de produtos e/ou serviços.

\section{Resultados - Objetivos Organizacionais}

Além da imagem organizacional, as entrevistas ressaltam que a contratação de funcionários deve atender à necessidades organizacionais. Argumenta-se a busca por qualificação, competência, comprometimento e foco.

(...) e sempre nós procuramos contratar da melhor forma, desejando procurar pessoas que vão atender as nossas necessidades. (E2, 2015)

(...) a maioria dos empresários eles procuram ver o comprometimento de cada colaborador. (E2, 2015)

(...) se você tiver apta entendeu, para o nível de trabalho ou daquilo que a empresa necessitar, não vejo nenhum tipo de preconceito em relação a isso aí não. (E6, 2015)

(...) ter foco naquilo que você conduz, naquilo que você vem predestinado ao seu trabalho, não vejo nenhum motivo de não contratar. $(\mathrm{E} 6,2015)$ 
O principal é ela desempenhar bem (...) é ela ter a qualificação pra aquele quadro, pra aquele cargo que a gente necessita $(\mathrm{E} 7,2015)$

Por sua vez, a busca por qualificação é condiciona ao reflexo da imagem que o funcionário projeta da reputação organizacional. Um entrevistado defende que há características elementares para a contratação. As normas institucionais, no entanto, são mais importantes e não devem ser negligenciadas.

(...)ele também tem que seguir as normas da empresa, e toda, e como toda empresa tem normas a gente não pode passar por cima das normas simplesmente porque ele é inteligente ou capacitado.(E1, 2015)

Em um cenário prospectivo, há relato no âmbito da configuração da gestão moderna, caracterizada pela leitura das competências profissionais e comportamentos organizacionais em única instância, como suficientes para o sucesso na contratação de novos funcionários.

Hoje um gestor moderno, que busca a tendência, eu acho que a pretensão dele é contratar pessoas comprometidas, que vá atingir os objetivos da empresa. (E2, 2015)

Os novos modelos de gestão indicam que a diversidade será gerida com vistas a adaptação organizacional às novas demandas dos mercados de trabalho e consumidor. As diferenças são parte da conjuntura social, da qual as organizações fazem parte e, por isso, a gestão da diversidade não apenas privilegia competência em detrimento das diferenças culturais, mas utiliza essas diferenças para agregar potencial às empresas, por meio da ampliação do leque de conhecimentos (Odorizzi, 2010, Cox \& Blake, 1991).

\section{Considerações Finais}

No percurso da análise da percepção de gestores de empresas sobre a empregabilidade de pessoas que fazem uso de tatuagens e piercings no contexto da gestão da diversidade cultural, dois aspectos emergiram para discussão: a cultura organizacional, 
formada por valores e relações interpessoais e, também, os resultados organizacionais, reunidos na imagem e nos objetivos institucionais.

No que tange a cultura organizacional, a investigação apontou valores pessoais e organizacionais marcados pelo estigma de que a tatuagem e o piercings não se adequam a um perfil profissional ideal para o mundo do trabalho, servindo à contextos específicos do mercado de trabalho, quando há valorização dessas marcas, como, por exemplo, o mercado da moda. Desses valores surgem diálogos para justificar uma postura de segregação: a inserção das empresas em uma cidade do interior do Estado do Piauí, arraigada por uma cultura tradicional.

Ainda no âmbito da cultura, além dos valores subjacentes, as relações interpessoais são mencionadas como maneira de relacionar a contratação de pessoas adeptas a tatuagens e piercings com a aceitação dos membros organizacionais. Nesse ponto, há duas perspectivas: quando, na visão do gestor, o grupo de colaboradores reprimem a presença da diversidade e, quando, sob outra perspectiva, outro grupo não diferencia seus membros, refletindo em uma boa integração. Sob tal fato, infere-se que a dificuldade de aceitação admitida aos membros organizacionais, na verdade, é reflexo da posição do próprio gestor que, por valorar a diversidade negativamente, busca justificativas para a não inclusão social.

Constata-se, então, nas empresas pesquisadas, em geral, não há gestão da diversidade, haja vista que os valores pessoais e organizacionais ainda não incorporaram valores culturais da diversidade. Reunidos, os três níveis de valores convergem para mudanças estruturais em função da necessidade de adaptação estratégica para que a diversidade seja elemento de maior harmonia no trabalho e oportunidade para agregar valor à organização (Torres \& Dessen, 2008, Bilky \& Jehn, 2008, Pettigrew, 1987, 2012, Cox \& Blake, 1991).

No que diz respeito à concepção dos gestores sobre a empregabilidade de pessoas adeptas a tatuagens e ao piercings e seu impacto nos resultados organizacionais, os diálogos direcionaram-se para a repercussão da reputação, em decorrência da imagem organizacional veiculada, comprometida com a adesão da diversidade representada pelo público pesquisado.

Por esse motivo, o discurso genérico confirma que as organizações investigadas condicionam suas ações em função dos valores sociais compreendidos como determinantes. Molda-se ao convite pelo tradicional numa concepção determinística que reflete pouca flexibilidade à novas demandas sociais. 
Ao mesmo tempo, há ênfase na necessária adoção de medidas compatíveis com os objetivos organizacionais, ao mesmo tempo que as normas sobrepõem a dimensão criativa e inovativa, bem como, seus resultados. Mais uma vez, há relação das concepções sobre diversidade, representada pelo uso de tatuagens e piercing, com a não empregabilidade, quando os objetivos institucionais refletidos nas políticas de gestão de pessoas, condicionam as competências, habilidades e atitudes profissionais ao atendimento de normas prescritas, reduzindo ou eliminando as possibilidades de gestão do potencial da diversidade na organização.

Dos dois polos de análise, resultados e cultura organizacional, encontra-se a emergência de uma nova concepção veiculada pela mídia, mesmo que ainda insipiente, que sugere uma necessidade de maior abertura do contexto laboral para se possa ter habilidade para negociar com os diversos stakeholders, em função de novas demandas sociais por consideração e respeito a diversidade.

Para tanto, a discussão sobre mudança e adaptação estratégica sugere novas leituras e análises no sentido de proporcionar análises voluntaristas e flexíveis à diversidade, em uma concepção de respeito aos seres humanos, em suas múltiplas representações e, também, como expressão de oportunidade competitiva, quando as diferenças somam-se em torno de novos produtos, serviços e negócios. Considera-se, portanto, que gestão para diversidade cultural valora as potencialidades dos sujeitos no sentido de maior engajamento para a eficácia organizacional. Nesse sentido, na fala dos gestores se pode evidenciar o quanto o uso de tatuagens e piercings podem contribuir na imagem e nos objetivos da organização.

O panorama da investigação condiz com os achados da pesquisa, a medida que tratase de uma cidade do interior do Piauí, região Nordeste do Brasil. Embora a diversidade cultural seja expressa nos mais variados contextos sociais, o limite da cultura tradicional pode prevalecer nesses ambientes, o que reflete em valores pessoais de gestores e em ações desfavoráveis à diversidade. Dessa forma, acredita-se que pesquisas em outras contextos, inclusive de natureza comparativa, pode agregar novos pontos de vista e ampliar a discussão da gestão da diversidade, no âmbito de sua afirmação como prática capaz de transformar organizações em espaços de maior acolhimento e mais competitivos. 


\section{Referências}

Bandeira-de-Mello, R. (2006). Softwares em pesquisa qualitativa. In C. K. Godoi, R. Bandeira-de-Mello, \& A. B. Silva (Orgs.). Pesquisa Qualitativa em Estudos Organizacionais: Paradigmas, Estratégias e Métodos. São Paulo: Saraiva.

Bar-Tal, D. (1997) Formation and Change of Ethnic and national Stereotypes: An integrative model. International Journal of Intercultural Relations, 21(4), p. 491-523.

Bardin, L. (2011). Análise de conteúdo. Lisboa: Edições 70.

Bauer, M. W., \& Gaskell, G. (2002) Pesquisa qualitativa com texto, imagem e som: Um manual prático. 5 ed. Petrópolis: Vozes.

Berger, M. (2006) Corpo e identidade feminina. (Tese de doutorado, Programa de Pós Graduação em Antropologia Social). Universidade de São Paulo, São Paulo.

Bhui, K., Stansfeld, S., Mackenzie, K., Karlsen, S., Nasroo, N., \& Weich, S. (2005) Racial/Ethnic Discrimination and common Mental Disorders Among Workers. Findings Jounal of Public Helth, 95(3).

Bilsky, W., \& Jehn, K. A. (2008). Cultura Organizacional e Valores individuais: evidências de uma estrutura comum. In M. L. M. Teixeira. Valores Humanos e Gestão: novas perspectivas. São Paulo: SENAC.

Borges, L. de O., \& Álvaro, J. L. (2013). O Psicólogo e as Relações de Trabalho. In L. O. Borges \& L. Mourão (Org.). O Trabalho e as Organizações: atuações a partir da Psicologia. São Paulo: Artmed.

Braz, C. A. de. (2006). Além da Pele: um olhar antropológico sobre a body modification em São Paulo. (Dissertação de Mestrado - Departamento de Antropologia do Instituto de Filosofia e Ciências Humanas). Universidade Estadual de Campinas, Campinas - SP.

Caroni, M. M., \& Grossman, E. (2012). As marcas corporais segundo a percepção de profissionais de saúde: adorno ou estigma? Ciência \& Saúde Coletiva, 17(4), p. 10611070, abr.

Coimbra, K. E. R., Pacheco, W. M., \& Saraiva, L. A. S. (2014). Além de Estereótipos 
Profissionais: O Cotidiano de Trabalhadores de Sex Shops. Gestão \& Regionalidade, 30(90), set-dez.

Coradini, J. R., \& Murini, L. T. (2009). Recrutamento e Seleção de Pessoal: Como Agregar Talentos à Empresa. Disciplinarum Scientia. Série: Ciências Sociais Aplicadas, 5(1), p. $55-78$.

Cox Jr., T., \& Blake, S. (1991) Managing cultural diversity: implications for organizational competitiveness. Academy of Management Executive, 5(3).

Fleury, A. R. D., \& Torres, A. R. R. (2007). Análise psicossocial do preconceito contra homossexuais. Estudos de Psicologia, 24(4), p. 475-486, Dec.

Freitas, H. M. R. de, Cunha Júnior, M. V.M. da, \& Moscarola, J. (1997). Aplicação de Sistemas de Software para Auxílio na Análise de Conteúdo. Revista de Administração, 32(3), p. 97-109, jul./set..

Gilbert, J., Carr-Rufino, N., Ivancevich, J. M., \& Lownes-Jackson, M. (2003) An empirical examination of inter-ethnic stereotypes: comparing Asian American and African American employees. Public Personnel Management. 32(2).

Goffman, E. (1988). Estigma: notas sobre a manipulação da identidade deteriorada. 4 ed. Rio de Janeiro: Guanabara.

Gonçalves, J. E. L. (1997). Os novos desafios da empresa do futuro. Revista de Administração de Empresas, 37(3), p. 10-19, Set.

Juto, A. M. B. (2012). A Gestão da Diversidade nas Companhias Aéreas que atuam no Brasil. (Dissertação de Mestrado, Programa de Pós-Graduação em Administração). Universidade Municipal de São Caetano do Sul, São Paulo.

Klaczynski, P. A., Goold, K. W., \& Mudry J. J. (2004). Culture, Obesity Stereotypes, SelfEsteem, and the "Thin Ideal”: A Social Identity Perspective. Journal of Youth and Adolescence, 33(4) 307-317.

Leitão, D. K. (2004). Mudança de significado da tatuagem contemporânea. Cadernos IHU Ideias, Rio Grande do Sul, 2(16). 
Michel, M. (2007). Tipos de Recrutamento e sua Importância para uma Gestão Adequada de Pessoas Aplicadas a Empresas. Revista Científica Eletrônica de Administração, Ano VII, Dezembro.

Minayo, M.C.S. (2007). O desafio do conhecimento: pesquisa qualitativa em saúde. São Paulo: Hucitec.

Monteiro, S. S., Villela, W. V., \& Soares, P. da S. (2014). É inerente ao ser humano! A naturalização das hierarquias sociais frente às expressões de preconceito $\mathrm{e}$ discriminação na perspectiva juvenil. Physis: Revista de Saúde Coletiva, 24(2), p. 421440.

Moreira, J. de O., Teixeira, L. C., \& Nicolau, R. de F. (2010) Inscrições corporais: tatuagens, piercings e escarificações à luz da psicanálise. Revista Latinoamericana de Psicopatologia Fundamental, 13(4), p. 585-598, Dec.

Myers, A. (2003). O valor da diversidade racial nas empresas. Estudos Afro-asiáticos, 25(3), p. 483-515.

Negri, A. D. (2011) Sobre Liberdade e Questões Pertinentes ao Preconceito Automático nas Sociedades Descentralizadas. Revista Brasileira de Direito Constitucional (RBDC), jan./jun., p. 209-223.

Neves, M. de A. (2013). Anotações sobre trabalho e gênero. Cadernos de Pesquisa, São Paulo, 43(149), p. 404-421, Ago.

Nkomo, S. M., \& Cox Jr., T. (2007). Diversidade e identidade nas organizações. In S. R. Clegg, C. Hardy, \& W. R. Nord (Org.). Handbook de estudos organizacionais: modelos de análise e novas questões em estudos organizacionais. São Paulo: Atlas.

Odorizzi, P. (2010). Discriminação Estética nas Relações de Trabalho. (Trabalho de Conclusão do Curso de Direito, Setor de Ciências Jurídicas). Universidade Federal do Paraná, Curitiba.

Osório, A. B. (2006). O gênero da tatuagem: continuidades e novos usos relativos à prática na cidade do Rio de Janeiro. (Tese de Doutorado - Programa de Pós-graduação em Sociologia e Antropologia). Universidade Federal do Rio de Janeiro, Rio de Janeiro. 
Paim, A. dos S. (2007). Aparência Física, Estereótipos e Inserção Profissional: um estudo sobre a profissão de Secretário Executivo segundo a percepção das estudantes de secretariado. (Dissertação de Mestrado em Psicologia). Universidade Federal da Bahia, Salvador.

Paim, A. dos S., \& Pereira, M. E. (2010). Estereótipos, boa aparência e a secretária executiva. Revista do Secretariado Executivo, Passo Fundo.

Pereira, J. B. C., \& Hanashiro, D. M. M. (2010). Ser ou não ser favorável às práticas de diversidade? eis a questão. Rev. adm. contemp., 14(4), p. 670-683, Ago.

Pérez, A. L. (2006). A identidade à flor da pele: etnografia da prática da tatuagem na contemporaneidade. Mana, 12(1), p. 179-206, Abr.

Pettigrew, A. (2012). Context and action in the transformation of the firm: A Reprise. Journal of Management Studies, 49(7), Nov., p. 1304-1328.

Pettigrew, A. (1987) Context and action in the transformation of the firm. Journal of Management Studies. 24(6), p.649-670.

Pires. C. B., Ott, E., \& Damacena, C. (2009). Guarda-Livros ou Parceiros de Negócios? Uma Análise do Perfil Profissional Requerido pelo Mercado de Trabalho para Contadores na Região Metropolitana de Porto Alegre. Revista Contabilidade Vista \& Revista, 20(3), p. 157-187, jul./set.

Rocha, G. (2009). A Arte da Tatuagem: A atividade ganha admiradores e supera antigos preconceitos. Eclética, Julho/Dezembro.

Rodriguez, L. da S., \& Carreteiro, T. C. O. C. (2014). Olhares sobre o corpo na atualidade: tatuagem, visibilidade e experiência tátil. Psicologia \& Sociedade, 26(3), p. 746-755.

Scanavez, S. M., \& Alves, R. (2009). As Organizações e o novo perfil dos colaboradores. Facesi em Revista. 1(2).

Silva, B. C. D. (2010). A Tatuagem na Contemporaneidade. (Trabalho de Conclusão do Curso de Artes Visuais). Universidade do Extremo Sul Catarinense, Criciúma - SC.

Silva, N., Zanelli, J. C., \& Tolfo, S. da R. (2013). Diagnóstico e Gestão da Cultura nas 
Organizações In L. O. Borges \& L. Mourão (Org.). O Trabalho e as Organizações: atuações a partir da Psicologia. Porto Alegre: Artmed.

Souza, J. J., \& Peixoto, A. de L. A. (2013). Os Novos Modelos de Gestão. In L. de O. Borges \&, L. Mourão (Org.). O Trabalho e as Organizações: atuações a partir da Psicologia. Porto Alegre: Artmed.

Tamayo, A. (2007). Hierarquia de valores transculturais e brasileiros. Psicologia: Teoria e Pesquisa, Brasília, 23.

Teixeira, M. L. M., \& Monteiro, R. S. (2008). Valores pessoais no ambiente de negócios. In M. L. M. Teixeira (Org.) Valores Humanos e Gestão: novas perspectivas. Editora SENAC-São Paulo.

Torres, C. V. \& Dessen, M. A. (2008). Valores Culturais brasileiros: desdobramentos teóricos. In M. L. M Teixeira (Org.). Valores Humanos e Gestão: novas perspectivas. São Paulo: SENAC.

Torres, C. V., \& Pérez-Nebra, A. R. (2004). Diversidade cultural no contexto organizacional. In J. C. Zanelli, J. E. Borges-Andrade, \& A. V. Bastos (Orgs). Psicologia Social e do Trabalho. Porto Alegre: Artmed.

Torrez Da Paz, M. das G., \& Neiva, E. R. (2008). Valores e mudança organizacional. In M. L. M. Teixeira (Org.), Valores Humanos e Gestão: novas perspectivas. São Paulo: SENAC.

Vergara, S. C. (2009). Projetos e Relatórios de Pesquisa em Administração. 11 ed. São Paulo: Atlas.

Weichselbaumer, D. (2000). Is it Sex or personality. The Impact of Sex Setereotypes on Discrimination in Applicant Selection, 11, University of Linz.

Zanelli, J. C., \& Silva, N. (2008). Interação humana e gestão: a construção psicossocial das organizações de trabalho. São Paulo: Casa do Psicólogo.

Submissão: 18/03/2016 Segunda Versão: 19/07/2016 

Detse Cultural: o Que Gestores Dizem Sobre Esse Tema? DOI: http://dx.doi.org/10.21714/2238-104X2016v6i2-28192

Aceite: 29/o8/2016 